\title{
Network Analysis of MicroRNAs, Transcription Factors, Target Genes and Host Genes in Human Breast Cancer
}

\author{
Zhuoyan HUANG ${ }^{1,2}$, Zhiwen XU ${ }^{1,2}$, Kunhao WANG ${ }^{1,2}$, Ning WANG ${ }^{1,2}$, Shang WANG ${ }^{1,2}$ \\ ${ }^{1}$ Jilin University, College of Computer Science and Technology \\ 2 Jilin University, Key Laboratory of Symbolic Computation and Knowledge Engineering of \\ Ministry of Education, Changchun, Jilin, CHINA
}

\begin{abstract}
This study constructs three regulatory networks of microRNAs (miRNAs) and genes in breast cancer (BC), and the abnormally expressed network may be the fault graph of BC's canceration, which helps us identify pathogenesis of BC. Scientists have identified genes and miRNAs as decisive biological factors in progression of BC. Insufficiently, research data of genes and miRNAs is unorganized and scattered, which made regulatory mechanism of BC still indeterminate. In the current study, we didn't only investigate one or several elements (miRNAs, TFs, target genes and host genes) associated with morbidity of BC. Instead, we systematically studied regulatory interactions among the whole elements relevant to BC and important regulatory pathways during BC's canceration. Then three regulatory networks (including the abnormally expressed network, related network and global network) are hierarchically constructed at three levels, aiming at analyzing significant miRNA-gene signaling pathways at the macroscopic level. Results shows the abnormally expressed network contains substantial faulty regulations between miRNAs and genes when BC occurs, and it may be underlying fault graph of BC's canceration. Significantly, if medical measure can be taken to correct each faulty regualtion to normal regulation, thus each genes and miRNAs will return to its normal expression level, and canceration of BC may be prevented and not occur. Furthermore, regulatory networks contain massive self-adaption feedbacks, which helps to understand the regulatory mechanism of BC. In conslusion, these networks, especially the abnormally expressed network, offers a systematical explanation about BC's pathogenesis, which may aid future research and therapy of BC.
\end{abstract}

Keywords: Breast cancer, MicroRNA, Transcription factor, Abnormally expressed, Network

ÖZET

Meme Kanserinde MicroRNAs, Transkripsiyon Faktörleri, Hedef Genler ve Host Genlerin Ağ Analizi

Bu çalışmada meme kanseri patogenezinini aydınlatabileceğini düşündüğümüz üç düzenleyici ağın microRNA (miRNA), genlerin analizi yapılmıştır. Bilim adamları meme kanserinde progresyon için belirleyici olan genleri ve miRNA'ları tespit etmişlerdir. Ancak meme kanserinin regülasyonunda gen ve miRNA'lar hakkında veriler yetersizdir. Bu çalışmada biz sadece bir iki gen veya miRNA çalışmadık. Biz meme kanserinde ve karsinogenezinde önemli düzenleyici etkileşimleri sistematik olarak çalıştık. Sonrasında üç düzenleyici (anormal olarak eksprese edilmiş ağlar dahil, ilgili yerel ağlar ve global ağlar) ağı hiyerarşik olarak üç seviyede inceledik, önemli miRNA- gen signal yolağını makroskopik düzeyde analiz ettik. Sonuçlarda anormal olarak eksprese edilmiş ağlar miRNA ve genlerin hatalı regülasyonu sonucu meme kanseri ve karsinogenezinde rol aldığını saptadık. Eğer etkin tıbbi tedavilerle herbir gen ve miRNA seviyeleri normal seviyelere getirilebilirse meme kanseri oluşumu önlenebilir. Bununda ötesinde, meme kanserindeki düzenleyici ağları anlamayı kolaylaştıran, düzenleyici ağlar kendi kendini ayarlama konusunda geri bildirimlere sahiptir. Sonuç olarak, bu ağlar, özelliklede anormal olarak eksprese edilen ağlar, meme kanseri patogenezini anlamaya ve gelecekte meme kanseri tedavisine yardımcı olacaktır.

Anahtar Kelimeler: Meme kanser, MicroRNA, Transkripsiyon faktörü, Anormal ekspressyon, Ağ 


\section{INTRODUCTION}

As the most common malignancy in woman body, breast cancer BC. causes hundreds of thousands of deaths every year. ${ }^{1}$ Recent years' statistical data shows that BC still has an increasing incidence. However, until now, the pathogeny of BC hasn't got a complete understanding. Numerous experiment data have indicated that genes and microRNAs miRNAs. are important biological factors during BC's biological activity. Among these factors, abnormally expressed genes and abnormally expressed miRNAs play a decisive role in mass regulatory pathways. PIK3CA is the most frequent mutated oncogene in breast cancer ${ }^{2}$, which is also present in other cancers. MiRNAs are also aberrantly expressed in $\mathrm{BC}^{3}$, such as hsa-miR-125b, hsa-miR-145, hsa-miR-155 and hsa-miR-21. What's more, over-expression of hsa-miR-133a in BC causes suppression of the level of phosphorylated p-Akt and inhibition of p-Akt nuclear translocation. ${ }^{4}$ Further, genes and miRNAs associated with $\mathrm{BC}$ but not abnormally expressed also effect BC's progression. Hsa-let-7 regulates renewal and tumorigenicity of BC's cells. ${ }^{5}$ The current study will mainly focus on abnormally expressed genes and miRNAs as well as their regulatory interactions to explain underlying mechanism of BC.

During the process of gene expression, scientists have identified that transcription factors TFs. and miRNAs are important regulators. ${ }^{6}$ By promoting or blocking the recruitment of RNA polymerase to specific genes, TFs bind to specific DNA sequences aiming at controlling the transcription. ${ }^{7,8}$

Besides, miRNAs play a role in transcriptional and post-transcriptional regulation in gene expression. ${ }^{9}$ By silencing or targeting genes, miRNAs often contribute to cancer's proliferation, differentiation and apoptosis. MiRNAs have been involved in many regulation activities and are easily abnormally expressed.

Genes which are targeted by miRNAs are usually called target genes. A miRNA may target one or several target genes. So target genes are important resources for studying regulatory relations between genes and miRNAs. To date, many databases can be used to further investigate regulatory mechanism of BC.
Genes in which miRNAs locate are called host genes. Study shows that miRNAs are transcribed in parallel with their host transcripts. ${ }^{10}$ And intronic miRNA and its host gene have close relation. ${ }^{11}$ MiRNAs and their host genes often co-regulate certain signalling pathways, which contributes to determining their roles in cell activity.

In this paper, we put all these elements associated with morbidity of $\mathrm{BC}$ together, and these elements include miRNAs, TFs, target genes and host genes. By studying their complex regulatory relations in signalling pathways, we attempt to explain the BC's canceration mechanism and give guide for cancer therapy. To date, much valuable research data and relevant literature are available to conduct the current study. With these data, three regulatory networks are established at three distinct levels, including the abnormally expressed network, related network and global network. Each network contains three kinds of regulatory relations, including TFs regulating miRNAs, miRNAs targeting target genes and host genes including miRNAs. The abnormally expressed network is the core transcriptional network, and it contains numerous regulatory interactions among TFs, miRNAs and genes. All the regulations are retrieved from experimentally validated data. The abnormally expressed network partially reveals BC's regulatory mechanism, and several important regulators as well as signalling pathways are clearly shown in it. Most significantly, the abnormally expressed network contains faulty regulations when BC occurs, so the network may be faulty graph of BC's canceration. This significance will guide further study and therapy research. The related network enlarges the abnormally expressed network, giving a wider understanding of BC's mechanism. Some TFs are predicted to add into the related network to attack future investigation. The global network contains all human cancers' regulatory relations. To clearly show BC's signalling pathways, upstream and downstream elements of abnormally expressed genes, miRNAs and predicted TFs in three networks are extracted to compare their similarities and differences. Outstanding elements and pathways are analyzed to uncover BC's pathogenesis. These results shown in three networks macroscopically expound canceration mechanism of $\mathrm{BC}$ and 
the abnormally expressed network should be given more research.

\section{MATERIALS AND METHODS}

\section{Material Collection and Data Processing}

First of all, experimentally validated dataset with regard to regulatory interactions among human miRNAs, TFs, target genes and host genes was collected. Human miRNAs and their experimentally validated target genes were extracted from the Tarbase http://diana.imis.athena-innovation. gr/DianaTools/index.php? $r=$ tarbase/index ${ }^{12}$ and miRTarBase http://mirtarbase.mbc.nctu.edu.tw/. ${ }^{13}$ Tarbase contains experimentally validated target genes with corresponding miRNAs and miRTarBase is a database of MiRNA-Target Interactions MTIs.. MiRNAs and genes symbols were unified by National Center of Biotechnology Information NCBI, http://www.ncbi.nlm.nih.gov/. ${ }^{14}$ This dataset was considered as U1. The dataset of human TFs and corresponding regulated miRNAs was selected from the TransmiR ${ }^{15}$, which is a TF-miRNA regulation database. The dataset was considered as U2. MiRNAs and their host genes were collected from the miRBase. ${ }^{16}$ and NCBI. This dataset was considered as U3.

Then, abnormally expressed genes and related genes of BC were separately collected. Genetic mutation genes, abnormally expressed proteins, single nucleotide polymorphisms SNPs. and overexpressed, downregulated, upregulated genes associated with $\mathrm{BC}$ were treated as abnormally expressed genes. We extracted the data from the Cancer Genetics Web http://www.cancerindex. org/geneweb/ ${ }^{17}$, NCBI SNP database http://www. ncbi.nlm.nih.gov/snp $/{ }^{18}$ and relevant literature. The dataset of abnormally expressed genes was considered as U4. Abnormally expressed genes were also considered as a part of related genes. Besides, we extracted related genes from GeneCards http:// www.genecards.org $/{ }^{19}$, which offered genetic and functional information of all known and predicted human genes. ${ }^{20}$ What's more, part of related genes was got by relevant literature, which mentioned that several genes had influence upon BC's grownth, migration and prevention. Furthermore, predicted TFs retrieved by P-match algorithm ${ }^{21}$ were added into related genes to deeply analyze transcriptional network of BC. We got 1000-nt nucleotide. promoter region sequences of abnormally expressed genes' target genes from UCSC database $^{22}$ Then P-match algorithm was applied to identify transcription factor binding sites TFBSs. in 1000-nt promoter region sequences. Finally we mapped these TFBSs onto promoter region of target genes. P-match algorithm combines pattern matching and weight matrix approaches, and matrix library of P-match is a set of known TFBSs collected in TRANSFAC, so it provides the possibility to search for a large variety of other TFBSs. The dataset of related genes was named as U5.

Finally, abnormally expressed miRNAs and related miRNAs were selected from research data. Abnormally expressed miRNAs, including overexpressed, downregulated and upregulated miRNAs, were mainly collected from mir2Disease ${ }^{23} \mathrm{http} / /$ www.mir2disease.org ${ }^{24}$, which collects abnormally expressed miRNAs in kinds of human diseases. The dataset of abnormally expressed miRNAs was called U6. Related miRNAs contain all the abnormally expressed miRNAs. Rest of related miRNAs were retrieved from relevant miRNA literature. The dataset of related miRNAs was called U7.

\section{Three Networks Construction}

To intuitively show relations among miRNAs, TFs, target genes and host genes, three regulatory networks were hierarchically established. Abundant elements with corresponding regulatory interactions in dataset U1, U2 and U3 were imported to construct the global network. Clearly, the global network is the experimentally validated regulatory network in human body, which overall reveals complex regulatory pathways when cancer occurs. If a pair of gene and miRNA separately from U4 and U6 can form specific relationship regulating, targeting or including. in the global network, then the pair with their interaction was added into the abnormally expressed network. So the abnormally expressed network of $\mathrm{BC}$ is part of the global network, and actually it is BC's experimentally validated transcriptional network. In the same method, the related network is formed with BC's related genes and related miRNAs dataset U5 and U7. as well as their interactions. CytoScape, a bioinformatics software for visualizing genes' interactions 


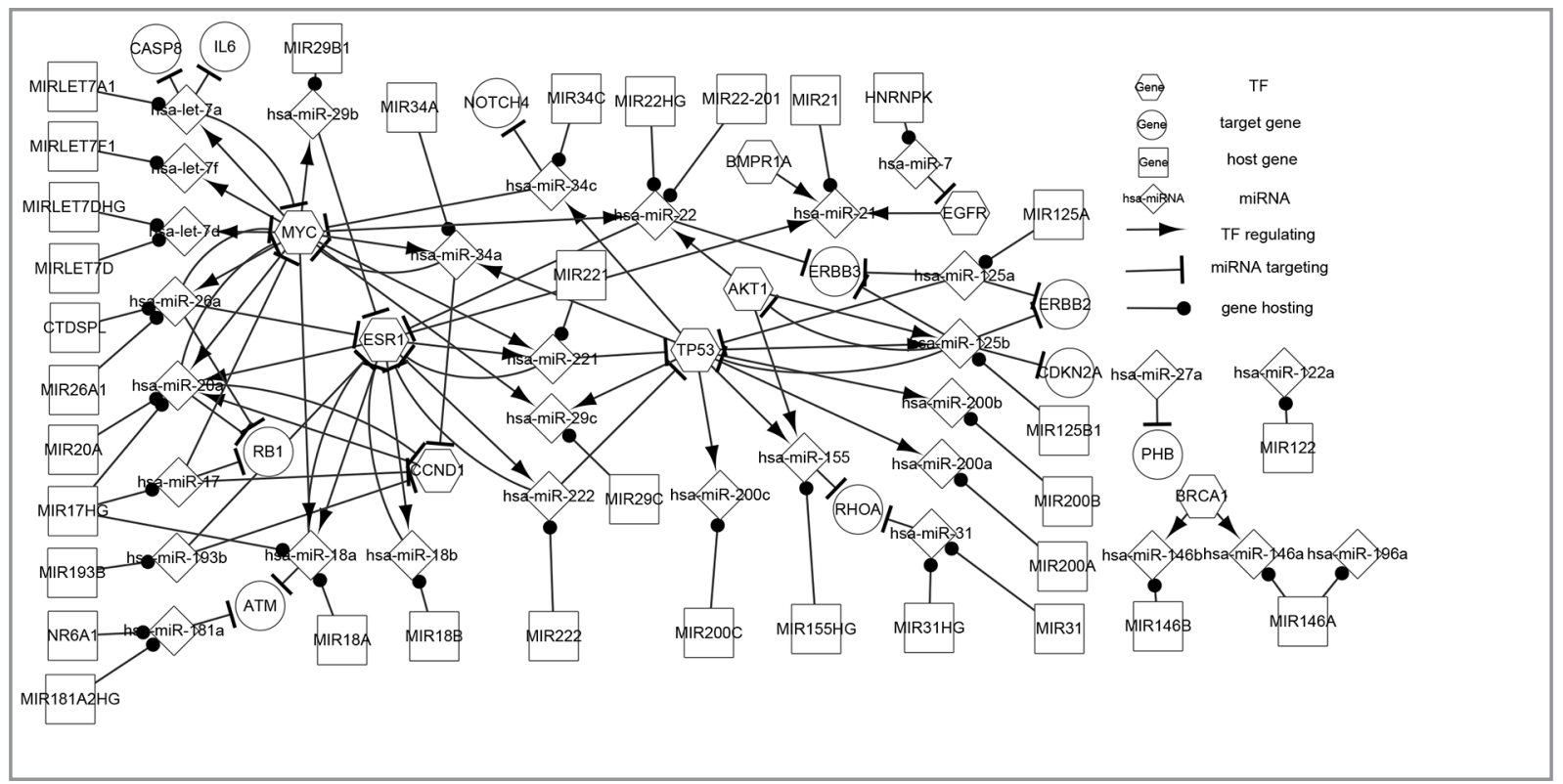

Figure 1. The abnormally expressed network of BC

network, was used for the three networks' visualization.

\section{RESULTS}

\section{The Abnormally Expressed Network of BC}

Significant network regulators and important regulatory pathways are distinctly shown in Figure 1. The abnormally expressed network exhibits three kinds of regulatory interactions among miRNAs, TFs, target genes and host genes, which are miRNAs targeting target genes, TFs regulating miRNAs, host genes including miRNAs. The abnormally expressed network may be BC's faulty graph in human body. These latent misregulations between genes and miRNAs should be repaired back to normal regulation state and need more research attention. It suggests that BC may be prevented and not occur if the abnormally expressed network of $\mathrm{BC}$ returns to its normal expression state.

The abnormally expressed network of BC consists of 8 TFs, 30 miRNAs, 10 target genes and 34 host genes. Except host genes, other elements perform abnormal expression. Each regulatory relation should be analyzed further, AKT1 regulates hsa-miR-125b, hsa-miR-20a targets CCND1 and NOTCH4 hosts hsa-miR-34c. These experimentally validated regulatory relations show some notable features. A miRNA can target one or sev- eral target genes while a TF may regulate one or several miRNAs. EGFR regulates hsa-miR-21 and TP53 regulates hsa-miR-155, hsa-miR-200a, hsamiR-200b, hsa-miR-200c, hsa-miR-29c, hsa-miR$34 \mathrm{a}$ and hsa-miR-34c. Hsa-miR-155 only targets RHOA and hsa-miR-20a targets CCND1, MYC and RB1. MiRNAs and TFs often form self-adaptation feedbacks, which implies that these TFs and miRNAs are controlled by each other and easily perform abnormal expression. The figure shows MYC regulates hsa-miR-34a and hsa-miR-34a targets MYC in return. It is suggested that these selfadaptation feedbacks respectively form several subnets to complete specific important biological process associated with $\mathrm{BC}$.

Besides, signalling pathways in the abnormally expressed network contains many characteristics. On one hand, some TFs regulate miRNAs without miRNAs' targeting. BRCA1 regulates hsa-miR146a and hsa-miR-146b, while no miRNAs target BRCA1. TFs like that may play an important role during BC's regulatory progression. Instead, some genes are always targeted by several miRNAs but don't regulate any miRNAs, which has a close relationship with BC's canceration. On the other hand, certain miRNAs only target genes without TFs' regulations. Hsa-miR-17 targets MYC, CCND1 and RB1, but no TFs regulate it. 


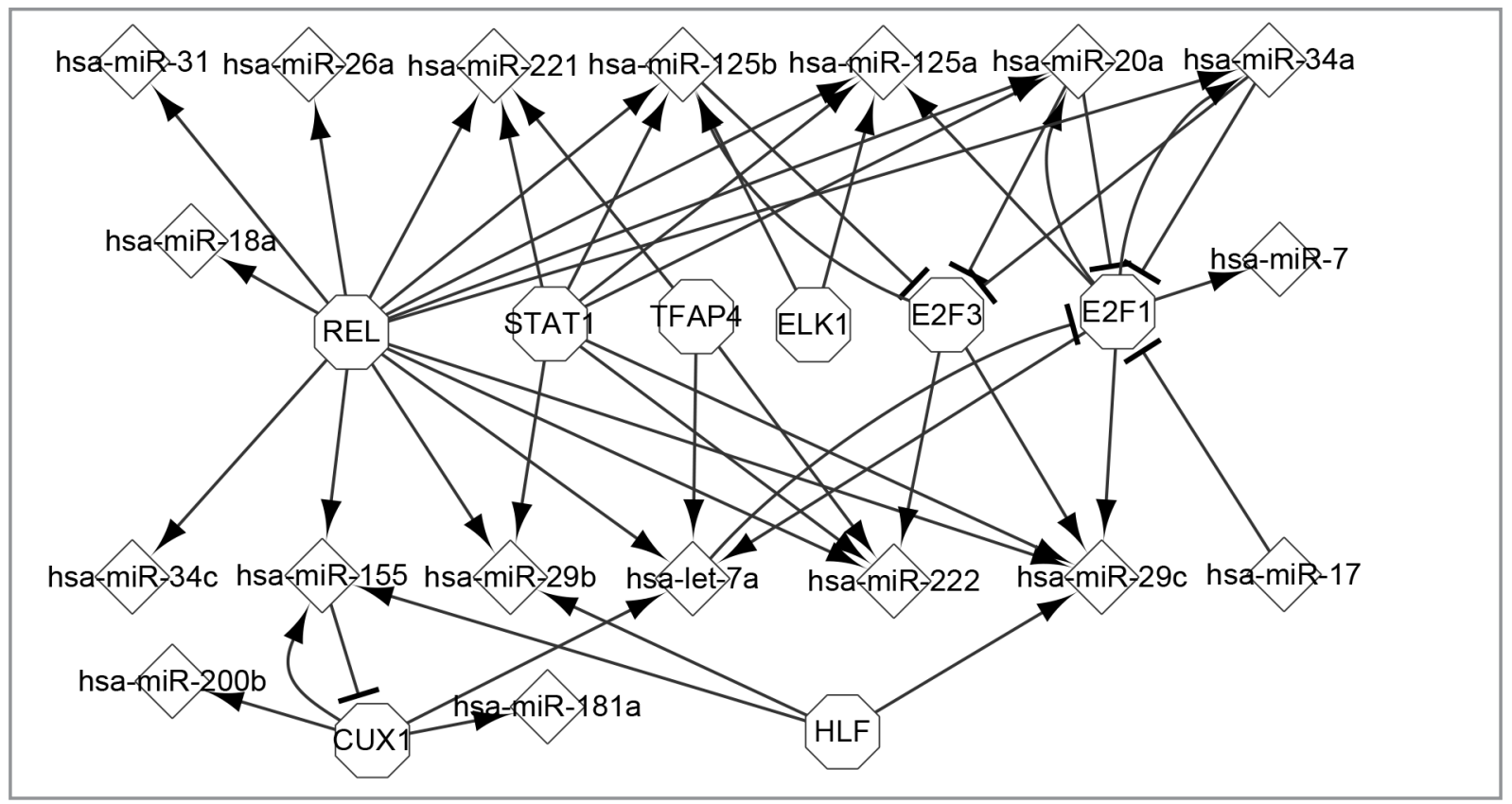

Figure 2. Regulatory network between predicted TFs and abnormally expressed miRNAs of BC

Another kind of miRNAs only receives TFs' regulation, such as hsa-miR-29c is regulated by MYC and TP53. Above especial elements can have vital influence on BC's proliferation, differentiation and apoptosis.

Figure 1 also hightlights several miRNAs along with their host genes. It can be concluded that a host gene may include one or several miRNAs, and a miRNA may locate in one or several genes. MIR146A includes hsa-miR-146a and hsa-miR196a, and hsa-miR-22 locates in two genes named MIR22HG and MIR22-201. What's more, some miRNAs should be paid more attention. In the figure, hsa-miR-18a and hsa-miR-20a, which both locate in MIR17HG, are both regulated by ESR1. Hsa-miR-17 and hsa-miR-20a which locate in MIR17HG both target MYC. The abnormally expressed network contains numerous topological regulatory interactions and these interactions are directly involved in BC's carcinogenesis. These transcriptional control relations could be used to repair misregulation of abnormally expressed genes and miRNAs, thus canceration of BC may not happen. Further study on abnormally expressed genes and miRNAs may contribute to deciphering pathogenesis of BC.

\section{The Related Network of BC}

The related network of $\mathrm{BC}$ not only includes the abnormally expressed network of $\mathrm{BC}$, but also demonstrates more regulations among related miRNAs, TFs and genes. The figure of the related network is omitted in consideration of its complexity. The related network contains 124 related genes and 84 related miRNAs. Compared to the abnormally expressed network, the related network shows extra interactions among related genes and miRNAs. Related TF named PTEN regulates hsa-miR-21 and hsa-miR-22, hsa-miR-20a extra targets a related gene named TGFBR2, except from targeting three abnormal expressed genes. The related network offers more references to discuss biological roles of genes and miRNAs in BC. The related network of $\mathrm{BC}$ gives more perspectives to identify function mechanism during BC's canceration.

\section{The Global Network}

The global network includes the abnormally expressed network of $\mathrm{BC}$ and the related network of BC. It consists of a large scale of experimentally validated regulations associated with genes and miRNAs in human body. The global network acts as a reference for the abnormally expressed network and related network. 


\section{Regulatory Network Between Predicted TFs and Abnormally Expressed miRNAs of BC}

To further investigate the underlying regulatory progression of $\mathrm{BC}, 8$ predicted TFs CUX1, E2F1, E2F3, ELK1, HLF, REL, STAT1 and TFAP4. as well as interactions with corresponding abnormally expressed miRNAs are concentrated on in Figure 2. Among predicted TFs, REL, E2F1, E2F3 and STAT1 are meant to play important roles in regulation progress. REL and STAT1 separately regulate 14 and 7 miRNAs while no abnormally expressed miRNAs target them. E2F1 regulates 6 miRNAs and is targeted by 4 miRNAs, in addition, E2F1 separately forms three self-adaptation relations with hsa-let-7a, hsa-miR-20a and hsa-miR34a. Similarly, E2F3 and hsa-miR-125b from a self-adaptation relation. Multiple self-adaptation regulations can establish several subnets to act as principal components in the network, which will determine certain pivotal signalling pathways. Certain regulatory pathways are identified to be significant. Predicted TF named HLF regulates hsa-miR-155a, then hsa-miR-155a targets CUX1, and then CUX1 regulates hsa-let-7a, hsa-miR-181a and hsa-miR-200b, meanwhile, CUX1 regulates hsa-miR-155a which forms a self-adaptation loop. It can be summarized that these elements constitute an ordered regulation chain to complete certain excellent bioprocess. A TF can regulate one or several miRNAs and a miRNA can target one or several TFs. A TF may indirectly control other TFs' function and expression through certain miRNAs. STAT1 regulates hsa-miR-20a which targets E2F3, so STAT1 indirectly controls E2F3 by hsa-miR20a's delivery. Regulatory interactions associated with predicted TFs may aid future mechanism investigation of $B C$.

\section{Comparison and Analysis on Upstream and Downstream of Abnormally Expressed genes}

Analysing genes, miRNAs as well as their regulations in three regulatory networks may be difficult to identify elements' role in signalling pathways. In our study, upstream regulators and downstream targets of all the abnormally expressed genes, abnormally expressed miRNAs and predicted TFs were additionally extracted from above three networks. Network elements which have upstream and downstream elements are emphatically discussed. It is suggested that regulatory pathways associated with several vital genes and miRNAs play a key role in BC's progression.

Upstream and downstream information of abnormally expressed genes in topological pathways are primarily studied. Here we select MYC as a significant model.

In Table 1, left 3 columns represent upstream regulators of MYC in three networks, and right 3 columns are MYC's downstream targets in three networks the same as Table 2 and Table $3 . .6$ miRNAs target MYC and MYC regulates 11 miRNAs in the abnormally expressed network, 9 miRNAs target MYC and 23 miRNAs are regulated by MYC in the related network, and 20 miRNAs target MYC and MYC regulates 42 miRNAs in the global network. 4 miRNAs, hsa-let-7a, hsa-miR-20a, hsamiR-26a and hsa-miR-34a, respectively form 4 self-adaption relations with MYC. These pathways have crucial influence on BC's development. Furthermore, upstream regulators of MYC can indirectly control downstream targets of MYC, such as hsa-miR-17 regulates hsa-miR-22's expression by MYC. Also, MYC can indirectly influence other elements, such as MYC indirectly regulates IL6 through hsa-let-7a. More similar regulatory interactions and self-adaption relations can be found in other two networks, which gives a wider understanding of BC's cancerization. Regulatory pathways associated with MYC may partly explain BC's biological mechanism.

\section{Comparison and Analysis on Upstream and Downstream of Abnormally Expressed miRNAs}

With analogous method, upstream and downstream elements of abnormally expressed miRNAs in three networks are also extracted, compared and analyzed. Notable genes regulate certain miRNA and certain miRNA targets several genes in return. Most of abnormally expressed miRNAs show similar features, and hsa-miR-20a is chosen as a case. Upstream and downstream elements of hsa-miR20a are indicated in Table 2. CCND1, ESR1 and MYC regulate hsa-miR-20a which targets CCND1, MYC and RB1 in the abnormally expressed network. In the related network, hsa-miR-20a targets 
International Journal of Hematology and Oncology

Table 1. Upstream and downstream information of MYC in three regulatory networks

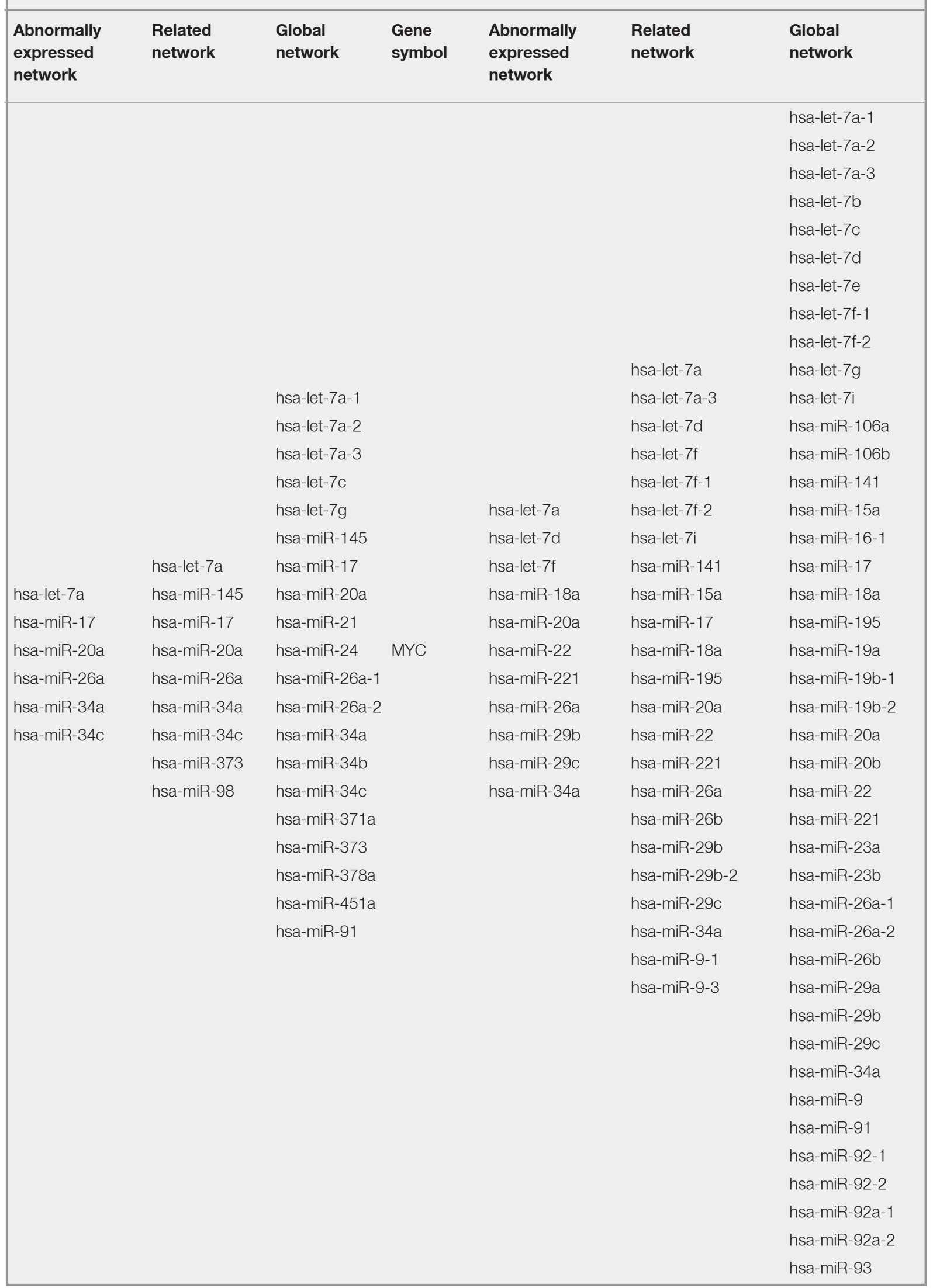


International Journal of Hematology and Oncology

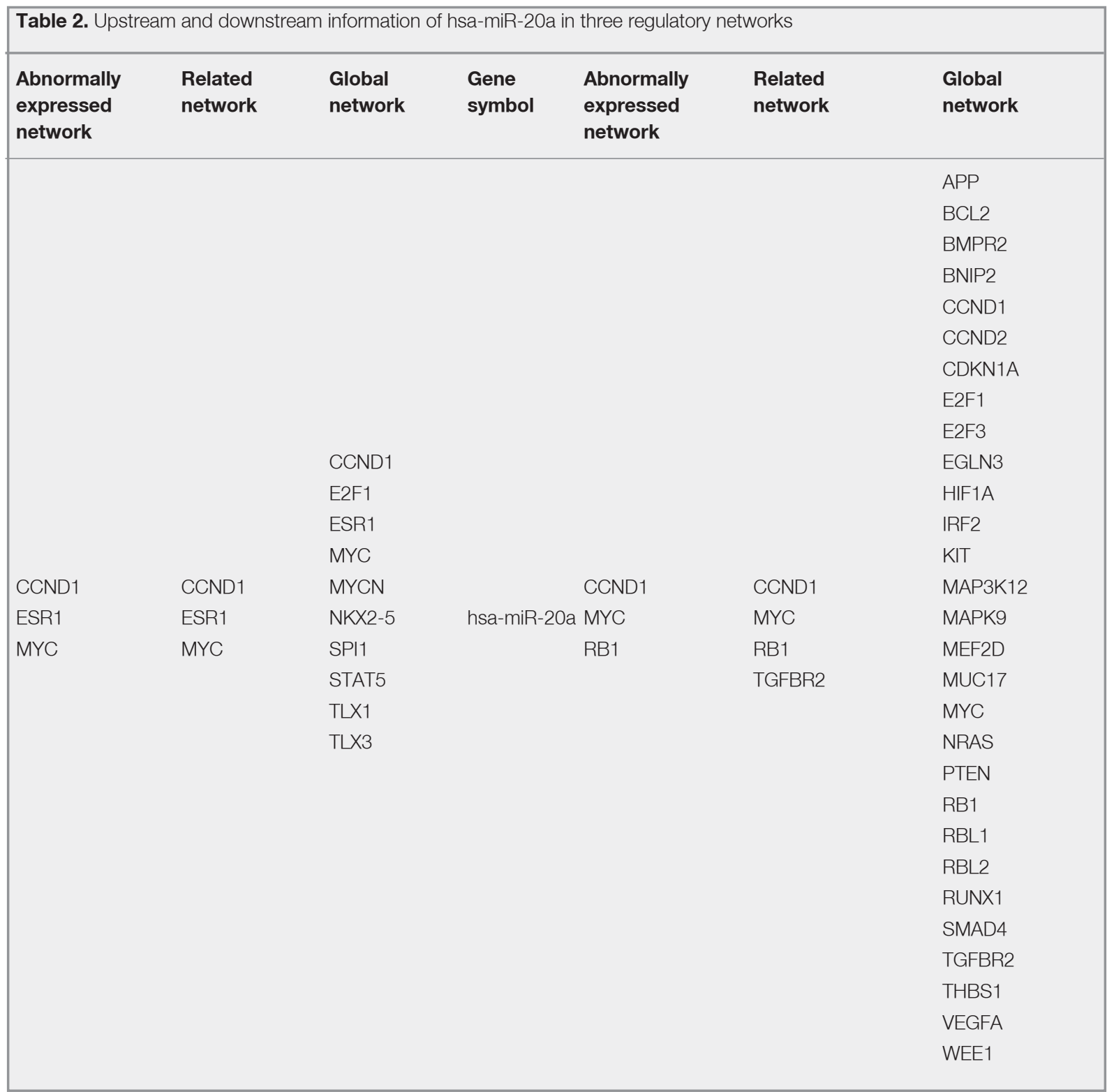

another gene called TGFBR2. 10 TFs regulate hsamiR-20a and hsa-miR-29 target genes are targeted by hsa-miR-20a in the global network. Upstream genes of hsa-miR-20a can regulate its downstream genes, thus contribute to numerous complex signal pathways. It can be seen CCND1 indirectly regulates MYC and RB1 by hsa-miR-20a in the abnormally expressed network of BC, and ESR1 indirectly controls CCND1, MYC, RB1 and TGF$\mathrm{BR} 2$ in the related network of BC. There exists two self-adaption regulations in the abnormally expressed network, CCND1 with hsa-miR-20a and MYC with hsa-miR-20a. These significant regulations play a role in $\mathrm{BC}$. Comparison and analysis of regulatory pathways of miRNAs aids researchers determine key role of miRNAs in BC.

\section{Comparison and Analysis on Upstream and Downstream of Predicted TFs}

Eventually, regulatory pathways associated with predicted TFs are analyzed. Exact biological role of predicted TFs remains to be validated in near future. We take E2F1 for an example to compare and study its upstream and downstream relations.

Upstream regulators and downstream targets of E2F1 in three networks are listed in Table 3. It is indicated that hsa-miR-34a targets E2F1 which

UHOD Number: 1 Volume: 26 Year: 2016 


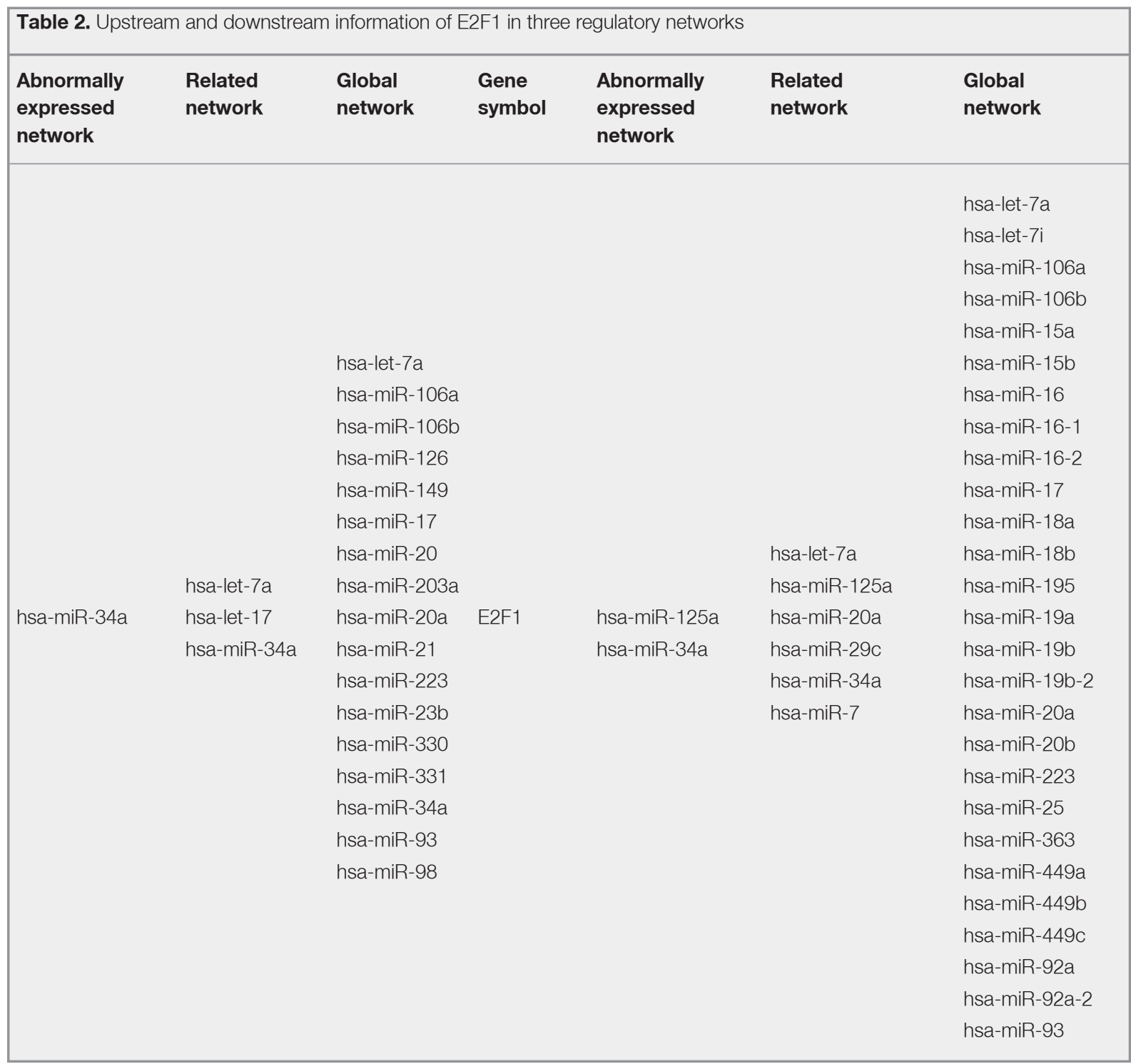

regulates hsa-miR-125a and hsa-miR-34a in the abnormally expressed network, hsa-let-7a, hsalet-17 and hsa-miR-34a target E2F1 which controls 6 miRNAs in the related network, and 17 miRNAs target E2F1 which regulates 27 miRNAs in the global network. It has been shown that hsamiR-34a and E2F1 form a self-adaption relation, suggesting E2F1's role in the transcriptional network. In the related network, another self-adaption pair hsa-let-7a and E2F1. is involved. Downstream miRNAs could be controlled by upstream miRNAs of E2F1 in many signalling pathways, such as hsamiR-34a indirectly regulates hsa-let-7a, hsa-miR125a, hsa-miR-20a, hsa-miR-29c and hsa-miR-7 through E2F1's adjustment. These outstanding ge- netic regulations about predicted TFs help a further investigation of BC's nosogenesis.

\section{DISCUSSION}

Years of hard researches have made great progress in investigating BC's pathogenesis. Research has shown that miRNAs and genes play significant roles in BC's physiological activity. ${ }^{25,26}$ Massive research findings associated with miRNAs and genes are not intuitive enough to determine BC's pathogenesis. A systematic and intuitive research method should be proposed to analyse BC's cause. The paper attempts to reveal etiopathogenesis of $\mathrm{BC}$, with a novel research approach that investigat- 
ing regulatory interactions among TFs, miRNAs and genes in overall level. Experimentally validated regulations among genes and miRNAs associated with $\mathrm{BC}$ are selected to construct three regulatory networks, including the abnormally expressed network, related network and global network. The three networks offer an intuitive angle to exhibit regulatory pathways across BC's progression.

The abnormally expressed network is the primary regulatory network. Numerous key regulations and important pathways are involved in the abnormally expressed network. Most of all, abnormally expressed network contains many abnormally expressed regulations when $\mathrm{BC}$ occurs, which suggests that abnormally expressed network is the cancer morbidity map of BC. So the abnormally expressed network can make great contribution to BC's prevention and treatment. The abnormally expressed network also contains several significant network regulators which play key roles in progression of BC. MiRNAs and TFs form self-adaption relations in the pathways, and these sort of regulations have important effect on BC's development.

The related network offers an extensional study for BC's canceration and those related miRNAs and genes can be investigated further according to the related network. Similar characteristics in the abnormally expressed network can be shown in the related network, too. Predicted TFs of BC also have notable effect in other cancers. E2F1 posttranscriptional regulation to the miR-106b-25 cluster contributes to development of gastric cancer. ${ }^{27}$ It can be seen that predicted TFs should be spent more research efforts and remain to be further validated in near furture.

The global network contains experimentally validated regulatory functions in human body, its valuable data is used to export the abnormally expressed network and related network of $\mathrm{BC}$. The global network is a worthwhile reference for cancer mechanism research and cancer treatment.

To intuitively analyse abnormally expressed elements' regulatory roles in complex miRNAgene signaling pathways, upstream regulators and downstream targets of abnormally expressed genes, miRNAs and predicted TFs are extracted to highlight important pathways. We have selected typical abnormally expressed elements, MYC, hsa-
miR-20a and E2F1, to analyze relative pathways. Researchers have identified that amplification of oncogene MYC has positive contribution to canceration of BRCA1-associated breast cancers. ${ }^{28,29}$ Increased expression of MYC has been found in triple-negative breast cancer tumor, which indicates MYC's prominent regulatory function. ${ }^{30}$ Scientists have found that hsa-miR-20a, which performs a lower expression in breast cancer's cells, directly regulates its target proteins to influence BC's metastatic heterogeneity. ${ }^{31}$ What's more, hsa-miR-20a shows a significant overexpression in $\mathrm{BC}$, which suggests a close association with $\mathrm{BC}$ 's canceration. ${ }^{32} \mathrm{E} 2 \mathrm{~F} 1$, as a significant role in the control of cell cycle, contributes to hormone adjustment and proliferation of $\mathrm{BC}$ by targeting its downstream genes..$^{33}$ It is concluded that upstream elements indirectly regulate downstream elements through certain gene and miRNA.

It is worthy of attention that some miRNAs and genes that are not abnormally expressed in $\mathrm{BC}$ show abnormally expressed in other carcinomas. For instance, PTEN induces HIF-2 activity by relieving YY1 in von hippel lindau null renal cell carcinoma while PTEN is not abnormally expressed in BC. ${ }^{34}$ This study considers that in furture study certain miRNA or gene should be analyzed and compared between similar cancers, thus we may identify exact function of it.

In conclusion, the current study emphatically points out that if abnormally expressed genes and miRNAs can be adjusted to normal state, we may properly control cancer's spread and development, even heal cancer theoretically. During the adjustment process, the abnormally expressed network can be the cancer morbidity map which gives useful guidance. The three networks, especially the abnormally expressed network of BC, probably contribute to mechanism and treatment research of $\mathrm{BC}$ in near future.

\section{Acknowledgments}

This work was supported by the grants from $\mathrm{Na}$ tional Natural Science Foundation of China No.60973091. and Science and Technology Development Plan of Jilin Province No.20130101166JC. 


\section{REFERENCES}

1. Al-Hajj M, Wicha MS, Benito-Hernandez A, et al. Prospective identification of tumorigenic breast cancer cells. Proc Nat Acad Sci USA 100: 3983-3988, 2003.

2. Bachman KE, Argani $P$, Samuels $Y$, et al. The PIK3CA gene is mutated with high frequency in human breast cancers. Cancer Biol Ther 3: 772-775, 2004.

3. Iorio MV, Ferracin M, Liu CG, et al. MicroRNA gene expression deregulation in human breast cancer. Cancer Res 65 7065-7070, 2005.

4. Cui WJ, Zhang S, Shan CL, et al. microRNA-133a regulates the cell cycle and proliferation of breast cancer cells by targeting epidermal growth factor receptor through the EGFR/Akt signaling pathway. FEBS J 280: 3962-3974, 2013.

5. Yu F, Yao H, Zhu PC, et al. let-7 regulates self renewal and tumorigenicity of breast cancer cells. Cell 131: 1109-1123, 2007.

6. Hobert $\mathrm{O}$. Gene regulation by transcription factors and microRNAs. Science 319: 1785-1786, 2008.

7. Roeder RG. The role of general initiation factors in transcription by RNA polymerase II. Trends Biochem Sci 21: 327-335, 1996.

8. Latchman DS. Transcription factors: an overview. Int J Biochem Cell Biol 29: 1305-1312, 1997.

9. Chen K, Rajewsky N. The evolution of gene regulation by transcription factors and microRNAs. Nat Rev Genet 8: 93103, 2007.

10. Rodriguez A, Griffiths-Jones S, Ashurst JL, Bradley A. Identification of mammalian microRNA host genes and transcription units. Genome Res 14: 1902-1910, 2004.

11. Baskerville S, Bartel DP. Microarray profiling of microRNAs reveals frequent coexpression with neighboring miRNAs and host genes. RNA 11: 241-247, 2005

12. http://diana.imis.athena-innovation.gr/DianaTools/index. php?r=tarbase/index (Access date: 06/02/2015).

13. http://mirtarbase.mbc.nctu.edu.tw/ (Access date: 06/02/2015

14. http://www.ncbi.nlm.nih.gov/ (Access date: 06/02/2015.)

15. Wang J, Lu M, Qiu CX, Cui QH. TransmiR: a transcription factor-microRNA regulation database. Nucleic Acids Res 38: D119-122, 2010

16. Kozomara A, Griffiths-Jones S. miRBase: integrating microRNA annotation and deep-sequencing data. Nucleic Acids Res 39: D152-157, 2011.

17. http://www.cancerindex.org/geneweb/ (Access date: 06/04/2015).

18. http://www.ncbi.nlm.nih.gov/snp/ (Access date: 06/04/2015).

19. http://www.genecards.org/ (Access date: 06/08/2015).

20. Safran M, Dalah I, Alexander J, et al. GeneCards Version 3: the human gene integrator. Database(Oxford), 2010. doi: 10.1093/database/baq020

21. Chekmenev DS, Haid C, Kel AE. P-Match: transcription factor binding site search by combining patterns and weight ma- trices. Nucleic Acids Res 33: W432-437, 2005

22. Fujita PA, Rhead B, Zweig AS et al. The UCSC Genome Browser database: update 2011. Nucleic Acids Res 39: D876-D882, 2011.

23. Jiang $Q H$, Wang $Y D$, Hao $Y Y$, Juan $L R$, Teng $M X$, Zhang $X J$, Li MM, Wang GH and Liu YL. miR2Disease: a manually curated database for microRNA deregulation in human disease. Nucleic Acids Res 37: D98-D104, 2009.

24. http://www.mir2disease.org/ (Access date: 06/08/2015).

25. Yu XF, Luo AP, Liu YC, et al. MiR-214 increases the sensitivity of breast cancer cells to tamoxifen and fulvestrant through inhibition of autophagy. Mol Cancer 14, 2015. doi: 10.1186/ s12943-015-0480-4.

26. Maqbool R, Rashid R, Ismail R, et al. The carboxy-terminal domain of connexin 43 CT-Cx43. modulates the expression of p53 by altering miR-125b expression in low-grade human breast cancers. Cell Oncol 38: 443-451, 2015.

27. Petrocca F, Visone R, Onelli MR. E2F1-regulated microRNAs impair TGF beta-dependent cell-cycle arrest and apoptosis in gastric cancer. Cancer Cell 13: 272-286, 2008.

28. Grushko TA, Dignam JJ, Das $\mathrm{S}$, et al. MYC is amplified in BRCA1-associated breast cancers. Clin Cancer Res 10: 499507, 2004.

29. Zhang XL, Farrell AS, Daniel CJ, et al. Mechanistic insight into Myc stabilization in breast cancer involving aberrant Axin1 expression. Proc Nat Acad Sci USA 109: 2790-2795, 2012.

30. Horiuchi D, Kusdra L, Huskey NE, et al. MYC pathway activation in triple-negative breast cancer is synthetic lethal with CDK inhibition. J Exp Med 209: 679-696, 2012.

31. Li JY, Zhang Y, Zhang WH, et al. Differential Distribution of miR-20a and miR-20b may Underly Metastatic Heterogeneity of Breast Cancers. Asian Pac J Cancer Prev 13: 1901-1906, 2012.

32. Leung CM, Chen TW, Li SC, et al. MicroRNA expression profiles in human breast cancer cells after multifraction and single-dose radiation treatment. Oncol Rep 31: 2147-2156, 2014.

33. Stender JD, Frasor J, Komm B, et al. Estrogen-regulated gene networks in human breast cancer cells: Involvement of E2F1 in the regulation of cell proliferation. Mol Endocrinol 21: 2112-2123, 2007.

34. Petrella BL, Brinckerhoff CE. PTEN suppression of $Y Y 1$ induces HIF-2 activity in von hippel lindau null renal cell carcinoma. Cancer Biol Ther 8: 1389-1401, 2009.

\section{Correspondence}

Professor Zhiwen Xu

Jilin University

College of Computer Science and Technology

No. 2699, Qianjin Street,

Changchun, Jilin 130012, P.R. CHINA

Tel: +0086-0431-85166475

Fax: +004-0431-85166475

E-mail: xuzw@jlu.edu.cn 